\title{
Design modern structure for heterojunction quantum dot solar cells
}

\author{
A. Thabet $^{1}$, S. Abdelhady ${ }^{2}$, Youssef Mobarak ${ }^{3}$ \\ ${ }^{1}$ Electrical Engineering Department, College of Engineering, Qassim University, Kingdom of Saudi Arabia \\ ${ }^{3}$ Electrical Engineering Department, Faculty of Engineering, King Abdulaziz University, Kingdom of Saudi Arabia \\ 1,2,3 Nanotechnology Research Center, Faculty of Energy Engineering, Aswan University, Egypt
}

\begin{tabular}{l} 
Article Info \\
\hline Article history: \\
Received Mar 25, 2019 \\
Revised Dec 5, 2019 \\
Accepted Dec 13, 2019 \\
\hline
\end{tabular}

Keywords:

Absorber

Energy conversion

Heterojunction

Quantum dot

Solar cell

\begin{abstract}
This paper proposal new structure for improving the optical, electrical characteristics and efficiency of $3^{\text {rd }}$ generation heterojunction quantum dot solar cell (HJQDSC) (ITO/CdS/QDPbS/Au) model by using the quantum dot window layer instead of bulk structure layers cell. Also, this paper presents theoretically analysis for the performance of the proposal HJQDSC (ITO/QDCdS/QDPbS/Au) structure. The new design structure was applied on traditional $(\mathrm{SnO} 2 / \mathrm{CdS} / \mathrm{CdTe} / \mathrm{Cu})$ and $(\mathrm{ZnO} / \mathrm{CdS} / \mathrm{CIGS} / \mathrm{Mo})$ thin film solar cells which based on sub-micro absorber layer thickness models by replacing the bulk CdTe, CIGS absorber layers and CdS window layer with quantum dot size materials to achieve higher efficiency with lesser usage layer material. Also, it has been studied the effect of using semiconductors layers in quantum dots size on electric and optical properties of thin film solar cells and the effect of window and absorber layers quantum dots radii on the performance of solar cells. Finally, a thermal efficiency analysis has been investigated for explaining the importance of new structure HJQD solar cells.
\end{abstract}

Copyright (C) 2020 Institute of Advanced Engineering and Science. All rights reserved.

\section{Corresponding Author:}

Safaa Abdelhady,

Department of Electrical Engineering,

Aswan University,

Sahary Road, Aswan 81528, Egypt.

Email: engsafaa33@gmail.com

\section{INTRODUCTION}

Several solar technologies including wafer, thin film and organic, have been researched to achieve reliability, cost-effectiveness and high efficiency. Cost effectiveness can be seen in the use of less material as well as increasing energy conversion efficiency. The reduction in the efficiencies of the previous models due to the reduction of absorber layers thickness are associated with a number of problems [1-3]. The $3^{\text {rd }}$ generation of solar cells technique based on novel absorber layer materials with tunable bandgap that can be tuned to match the spectral distribution of solar spectrum are crucial and achieved less consummation absorber layer material. Quantum dots have the merit of tunable bandgap as a result of size variation as well as formation of intermediate bands. The energy band gap increases with a decrease in size of the quantum dot, the adjustable bandgap of quantum dots allows the construction of nanostructured solar cell that is able to harvest more of the solar spectrum [4]. Quantum dots can generate multiple exciton (electron-hole pairs) after collision with one photon of energy exceeding the band gap. Absorption of UV photons in quantum dots produces more electrons than near infrared photons. Quantum dots emit up to three electrons per photon due to multiple exciton generation as opposed to only one for standard crystalline silicon solar cell [5]. The previous study for heterojunction solar cells based on $\mathrm{PbS}-\mathrm{QDs} / \mathrm{CdS}$ thin films demonstrating an achieved efficiency of $3.3 \%$ [6]. 
This paper proposal new structure for previous heterojunction quantum dot ITO/CdS/QDPbS/Au thin film solar cell model to improve the efficiency of the model by using the quantum dot absorber layer and replaced the bulk CdS window layer with quantum dot $\mathrm{CdS}$ layer. It has been applied the new structure model on the previous $\mathrm{SnO}_{2} / \mathrm{CdS} / \mathrm{CdTe} / \mathrm{Cu}$ and $\mathrm{ZnO} / \mathrm{CdS} / \mathrm{CIGS} / \mathrm{Mo}$ thin film models which based on sub-micro absorber layer thickness to improve the performance and efficiency of the cells to save the consumption in the absorber layer material. The effect of window and absorber layers' quantum dots radii on the performance of the selected cells. A comparative study is done for specifying the best size of window and absorber layer materials to achieve higher efficiency with lesser usage semiconductor materials and lesser production cost and time.

\section{MATHEMATICAL MODELS OF PROPOSAL HJQD THIN FILM SOLAR CELLS}

Considering spherical shape of nanostructure layer material in thin film solar cell, based on the model developed by Louis Brus for colloidal quantum dots. The energy band gap of quantum dot layer material can be approximated by 1 , and that bandgap energy values increase as the quantum dot size decreases [7].

$$
E_{g(Q d o t s)}=E_{g b u l k}+\frac{\pi^{2} h^{2}}{2 R^{2}}\left(\frac{1}{m_{e b}}+\frac{1}{m_{h b}}\right)-\frac{1.8 Q^{2}}{4 \pi \varepsilon_{b} \varepsilon_{o} R}
$$

where: $\mathrm{R}$ is radius of quantum dot layer material, $\mathrm{m}_{\mathrm{eb}}, \mathrm{m}_{\mathrm{hb}}$ are the effective mass of electron and hole for layer material, $\mathrm{Q}$ is the elementary charge, $\varepsilon_{0}$ is the permittivity of free space, and $\mathrm{h}$ is Plank constant. The energy bandgap value of the bulk layer material calculated using Varshni relation temperature dependence of the bandgap in semiconductors which using in absorber or window layer can be described as [8-10].

$$
E_{g b u l k}=E_{g}(0)-\frac{\zeta T^{2}}{\beta}
$$

where, $E_{g}(0)$ is energy band gap of semiconductor material at zero temperature, $\zeta$ and $\beta$ are constants, $\varepsilon_{\mathrm{b}}$ is dielectric constant of the semiconductor layer material which can be described by using the Drude model [11-12] as follows:

$$
\varepsilon_{b}=\varepsilon_{b \infty}\left(1-\frac{\omega_{b}^{2}}{\omega^{2}+i \omega\left(\gamma_{m b}\right)}\right)
$$

where, $\omega$ is angular frequency of light, $\omega_{0}$ is the plasma angular frequency of semiconductor layer material, $\gamma_{\mathrm{mb}}$ is the damping frequency of semiconductor layer material. Whatever, $\varepsilon_{\mathrm{b} \infty}$ is the infinity dielectric constantof semiconductor layer materials that can be determined as follows:

$$
\varepsilon_{b \infty}=\varepsilon_{o}\left(1+\frac{\omega_{b}^{2}}{\left(E_{g b u l k}\right)^{2}}\right)
$$

Also, $G_{Q D}$ is the electron-hole pair generation rate in the quantum dot absorber layer can be written with the aid of the following [13]:

$$
G_{Q D}(\lambda)=\frac{\alpha_{b Q D}(\lambda) e^{-\alpha_{w Q D}\left(d_{w}\right)}\left[1-R_{Q D}(\lambda)\right] \lambda I_{o}(\lambda)}{h c}
$$

where, $\lambda$ is the photon wavelength, $\alpha_{w Q D} d_{w}$ is the absorption coefficient and thickness of the thin top semiconductor layer (n-layer CdS), $\alpha_{b Q D}$ is the absorption coefficient of the absorber layer (CdTe, GIGS or $\mathrm{PbS}), R_{Q D}(\lambda)$ is reflection of front layer material $\left(\mathrm{SnO}_{2}, \mathrm{ZnO}\right.$ or ITO), and $I_{o}(\lambda)$ is the intensity of the solar spectral, $c$ is the speed of light. The absorption coefficient of the absorber and window quantum dots layers $\left(\alpha_{b Q D}(\lambda)\right.$ and $\left.\alpha_{w Q D}\right)$ can be calculated based on the Beer-Lambert's law as follows [14]:

$$
\alpha_{Q D}(\lambda)=\frac{2.303 \times A_{t Q D}}{d_{t}}
$$

where, $A_{t Q D}$ is the absorbance of the absorber or window layer that calculated as follows:

$$
A_{t Q D}=1-T_{t e f Q D}-R_{t e f Q D}
$$


also, $R_{t e f Q D}$ and $T_{\text {tefQD }}$ are the reflectance and transmittance of quantum dot window or absorber layer that evaluated from the following [15]:

$$
R_{t e f Q D}=\frac{P_{Q D}{ }^{2}+Z_{Q D}{ }^{2}+2 P_{Q D} Z_{Q D} \cos \Theta}{1+2 P_{Q D}{ }^{2} Z_{Q D}{ }^{2}+2 P_{Q D} Z_{Q D} \cos \Theta}, \text { and } T_{t e f Q D}=\frac{16 n_{0}^{2} n_{t Q D}^{2} n_{S}}{1+2 P_{Q D}{ }^{2} Z_{Q D}{ }^{2}+2 P_{Q D} Z_{Q D} \cos \Theta}
$$

The refractive index or substrate of quantum dot thin film material $\left(n_{t Q D}, n_{s Q D}\right)$ window or absorber layer has been calculated as follows:

$$
n_{b Q D}=\sqrt{\frac{\left|\varepsilon_{b Q D}\right|+\varepsilon_{r e b Q D}}{2}}
$$

The dielectric constant of the quantum dot semiconductor layer material, which can be described by using the Drude model with respect to $[11,12,16,17]$ as follows:

$$
\varepsilon_{b Q D}=\varepsilon_{b \infty Q D}\left(1-\frac{\omega_{b}^{2}}{\omega^{2}+i \omega\left(\gamma_{a}\right)}\right), \text { and } \varepsilon_{b \infty Q D}=\varepsilon_{o}\left(1+\frac{\omega_{b}^{2}}{\left(E_{g(Q d o t s)}\right)^{2}}\right)
$$

The refractive index of front thin film layer material $\left(\mathrm{ZnO}\right.$, ITO or $\left.\mathrm{SnO}_{2}\right) n_{x}$ calculated using sellmeier equations $[18,19]$. The substrate layer material of absorber layer is metallic material $(\mathrm{Cu}, \mathrm{Au}, \mathrm{Mo})$. The dielectric constant of the metallic material $\varepsilon_{m}$ can be described as [16]:

$$
\varepsilon_{m}=\varepsilon_{I N T R A}+1-\frac{\omega_{m}^{2}}{\omega^{2}+i \omega\left(\gamma_{m}\right)}
$$

where, $\gamma_{\mathrm{m}}$ is the macroscopic damping constant due to the dispersion of the electrons by the ions of the system of metallic, $\omega_{\mathrm{m}}$ is the plasma angular frequency, $\varepsilon_{\text {INTRA }}$ is the contribution from the intra-band transitions. The refractive index of substrate layer material of absorber layer calculated using the dielectric constant of metallic substrate layer $\varepsilon_{\mathrm{m}}$ the forward diode current of proposal heterojunction quantum dot cells can evaluate [13] as:

$$
\begin{aligned}
& J_{d i Q D}(V)=J_{O Q D}\left[\exp \left(\frac{Q\left(V+J(V) R_{s e r}\right)}{n K T}\right)-1\right] \\
& J_{O Q D}=\frac{W_{Q D} Q \sqrt{N_{c o n} N_{v a l} \exp \left(-\frac{E_{g b Q D}}{K T}\right)}}{\sqrt{{ }^{t^{t} h}}}
\end{aligned}
$$

where, $J_{O Q D}$ is reverse saturation current density in quantum dot cells, $n$ is the diode quality factor, $R_{\text {ser }}$ is series resistance. The width of the depletion layer depends on the dielectric constant of quantum dot absorber layer material $\varepsilon_{b Q D}$ that can be calculated by the following expression [20].

$$
W_{Q D}=\sqrt{\frac{2 \varepsilon_{0} \varepsilon_{b Q D}\left(V_{b i}-V\right)}{Q\left(N_{a}-N_{d}\right)}}
$$

where $V_{b i}$ is the built-in potential, $N_{a}-N_{d}$ is the concentration of uncompensated acceptors. Whatever, total photo generated current density, the open circuit voltage, efficiency and fill factor of proposal heterojunction quantum dot models can be obtained [13] as:

$$
J_{p h Q D}(V)=\int_{0}^{\infty} J_{T Q D}(\lambda \cdot V) d \lambda
$$

The resultant photocurrent density $J_{T Q D}(\lambda . V)$ dependent on the generation rate and depletion width of heterojunction quantum dot cell based on [13]. The net external current density from proposal heterojunction quantum dot a solar cell obtained by the following expression [21]:

$$
V=J_{p h Q D}(V)-J_{d i Q D}(V)-\left(\frac{V+J(V) R_{s e r}}{R_{s h}}\right)
$$


where, $R_{s h}$ is the shunt resistance, $\mathrm{V}$ is the applied voltage. Moreover, the open circuit voltage of quantum dot thin film solar equation is expressed as follows [22]:

$$
\begin{aligned}
& V_{O C Q D}=\left(\frac{K T}{Q}\right) \ln \left[\frac{J_{P h Q D}}{J_{O Q D}}+1\right] \\
& P_{Q D}=J \times V
\end{aligned}
$$

where: $P_{\max Q D}$ is the maximum point of output power density of quantum dot cell which calculate from $P_{Q D}-\mathrm{V}$ curve. Final form of efficiency and Fill factor of quantum dot thin film solar cell calculated by the following expression [22]:

$$
\begin{aligned}
& F . F Q D=\frac{P_{\max Q D}}{V_{O c Q D} \times J_{p h Q D}} \\
& n_{Q D}=\frac{J_{p h Q D} V_{O C Q D} F \cdot F Q D}{P_{\text {in }}} \times 100
\end{aligned}
$$

\section{QUANTUM SOLAR CELLS PARAMETERS}

The proposal models are used parameters of traditional practical models by using new techniques, thus, it has been achieved new high efficiency quantum dot solar cells with smallest absorber and window layer thickness for saving the consumation of materials and hence reducing the cost [2, 3, 6]. Tables 1-3 depicts the main parameters of proposal heterojunction quantum dot thin film models.

\begin{tabular}{|c|c|c|c|c|}
\hline Parameters & CdTe & CIGS & $\mathrm{PbS}$ & $\mathrm{CdS}$ \\
\hline Bulk energy band gap $(\mathrm{eV})$ at room temperature & 1.5 & 1.10 & 0.395 & 2.40 \\
\hline Bulk absorption coefficient $\times 10^{5} \mathrm{Cm}^{-1}$ & 0.4 & 0.50 & 0.008 & 0.9 \\
\hline Absolute bulk dielectric constant & 9.5 & 13.6 & 18.6 & 10.2 \\
\hline Band gap (eV) at zero Kelvin & 1.6077 & 1.25 & 0.543 & 2.58 \\
\hline Band gap parameter $\mathrm{G}\left(\mathrm{eVK}^{-1}\right) \times 10^{-4}$ & 3.1 & 1.02 & 5 & 4.202 \\
\hline Band gap parameter $\beta(\mathrm{K})$ & 108 & 272 & 0.40 & 147 \\
\hline Electron mobility $\left(\mathrm{Cm}^{2} / \mathrm{Vs}\right)$ & 320 & 100 & 1000 & 350 \\
\hline Hole mobility $\left(\mathrm{Cm}^{2} / \mathrm{Vs}\right)$ & 40 & 25 & 80 & 50 \\
\hline Effective mass of electron & 0.11 & 0.09 & 0.1 & 0.2 \\
\hline Effective mass of holes & 0.35 & 0.75 & 0.1 & 0.7 \\
\hline Plasma angular frequency $\left(\omega_{p} \times 10^{16} \mathrm{rad} / \mathrm{s}\right)$ & 0.052 & 0.039 & 0.014 & 0.082 \\
\hline Damping constant $\left(\gamma_{m} \times 10^{13} \mathrm{~s}^{-1}\right)$ & 8.88 & 19.5 & 1.76 & 17.6 \\
\hline Fermi velocity $\left(v_{f} \times 10^{6} \mathrm{~m} / \mathrm{s}\right)$ & 0.59 & 0.45 & 8 & 0.89 \\
\hline
\end{tabular}

Table 1. Parameters of usage substrate materials for absorber layer [23-25]

\begin{tabular}{ccc}
\hline Materials & Plasma angular frequency $\left(\omega_{p} 10^{16} \mathrm{rad} / \mathrm{s}\right)$ & Damping constant $\left(\gamma_{m} 10^{13} \mathrm{~s}^{-1}\right)$ \\
\hline Cupper $(\mathrm{Cu})$ & 1.03 & 5.26 \\
Gold $(\mathrm{Au})$ & 1.29 & 0.549 \\
Molybdenum & 0.19 & 1.14 \\
\hline
\end{tabular}

Table 2. Parameters of usage materials [2, 3, 6, 26]

Table 3. Parameters of usage thin film solar cells models $[2,3,6]$

\begin{tabular}{cccc}
\hline Parameters & $\mathrm{SnO}_{2} / \mathrm{CdS} / \mathrm{CdTe} / \mathrm{Cu}$ & $\mathrm{ZnO} / \mathrm{CdS} / \mathrm{CIGS} / \mathrm{Mo}$ & $\mathrm{ITO} / \mathrm{CdS} / \mathrm{QDPbS} / \mathrm{Au}$ \\
\hline Absorber layer thickness $(\mathrm{nm})$ & 500 & 360 & 200 \\
Window layer thickness $(\mathrm{nm})$ & 100 & 40 & 70 \\
Front layer thickness $(\mathrm{nm})$ & 100 & 450 & 100 \\
Electron lifetime $(\mathrm{s})$ & $1 \times 10^{-8}$ & $16 \times 10^{-7}$ & $16 \times 10^{-5}$ \\
Hole lifetime (s) & $5 \times 10^{-8}$ & $1.6 \times 10^{-5}$ & $10^{-5}$ \\
$N_{a}-N_{d}$ the concentration of & $2.44 \times 10^{12}$ & $7.56 \times 10^{13}$ & $0.19 \times 10^{10}$ \\
uncompensated acceptors $\left(\mathrm{cm}^{-3}\right)$ & & & 1.4 \\
Diode quality factor & 1.6 & 2.5 & 2.1 \\
Series resistance $\left(\Omega . \mathrm{Cm}^{2}\right)$ & 1.08 & 320 & 204 \\
Shunt resistance $\left(\Omega . \mathrm{Cm}^{2}\right)$ & & &
\end{tabular}




\section{RESULTS AND ANALYSIS}

Quantum dot size can be employed in all solar cells to reduce cost by saving usage materials size, enhance absorption and efficiency by controlling the size of the quantum dot size, since several properties can change due to any decrease in the size of the nanoparticles. This work discusses the benefit of reducing the quantum dot radii absorber and window layer radii on the performance of the heterojunction quantum dot thin film solar cells (ITO/QDCdS/QDPbS/Au), (ZnO/QDCdS/QDCIGS/Mo), ( $\left.\mathrm{SnO}_{2} / \mathrm{QDCdS} / \mathrm{QDCdTe} / \mathrm{Cu}\right)$ models.

\subsection{Optical characterization of quantum dot layers}

Figure 1 shows radii effect on the refractive index and dielectric constant of quantum dot semiconductors $\mathrm{CdS}, \mathrm{CdTe}, \mathrm{CIGS}$ and $\mathrm{PbS}$ at wave length 500nm. It has been depicted that the refractive index and absolute dielectric constant of quantum dot (CdS, PbS, CIGS and CdTe) semiconductors have been lower than the refractive index and dielectric constant of bulk materials; because of decreasing the semiconductor material size. On the other hand, Figure 2 describes the effect of nanoparticles radii of quantum dot semiconductors layers (CdTe, $\mathrm{CdS}, \mathrm{PbS}$ and CIGS) on the absorption coefficient and energy band gap at wave length $500 \mathrm{~nm}$ and thickness $700 \mathrm{~nm}$.

\subsection{New heterojunction quantum dot thin film solar cells}

Figure 3 illustrates the short circuit current density, open circuit voltage, fill factor and efficiency of heterojunction quantum dot $\mathrm{SnO}_{2} / \mathrm{QDCdS} / \mathrm{QDCdTe} / \mathrm{Cu}$ thin film solar cell with variant quantum dots $\mathrm{CdS}$ and CdTe radii. Whatever, Figure 4 describes the short circuit current density, open circuit voltage, fill factor and efficiency of heterojunction quantum dot Zno/QDCdS/QDCIGS/Mo thin film solar cell with variant of quantum dots CdS and CIGS radii. Figure 5 describes the short circuit current density, open circuit voltage, fill factor and efficiency of heterojunction quantum dot ITO/QDCdS/QDPbS/Au thin film solar cell with variant radii of quantum dot $\mathrm{CdS}$ and $\mathrm{PbS}$. The traditional performance of heterojunction $\mathrm{CdS} / \mathrm{QDPbS}$ has been enhanced by replacing the $\mathrm{CdS}$ and QDPbS layer with quantum dot QDCdS and QDPbS layers at radii $1 \mathrm{~nm}$ or $1.35 \mathrm{~nm}$. It is noticed that. the best nanoparticles radii for window and absorber layers is $1 \mathrm{~nm}$ for enhancing the open circuit voltage, short circuit current density, fill factor and energy conversion efficiency of the cell.

\subsection{Comparison between traditional and heterojunction quantum dots solar cells}

Figure 6 illustrated the benefit of using quantum dot size of window layer CdS instead of bulk one enhanced the absorption of window layer which result more enhancement in J-V and P-V characteristics. The enhancement in the J-V and P-V characteristics of traditional practical model has been occurred by using window layer $\mathrm{CdS}$ and absorber layer CdTe in quantum dot size with radii $1 \mathrm{~nm}$ as shown in Figure 7. On the other hand, Figure 8 shows J-V and P-V characteristics of practical ZnO/CdS/CIGS/Mo model and proposal heterojunction quantum dot ZnO/QDCdS/QDCIGS/Mo thin film solar cell. Table 4 depicts the comparison in the performance of practical previous models $[2,3,6]$ and the heterojunction quantum dot proposal models at room temperature. The table show that the performance of selected models has been enhanced by using window layer and absorber layer in quantum dot size with radii $1 \mathrm{~nm}$.

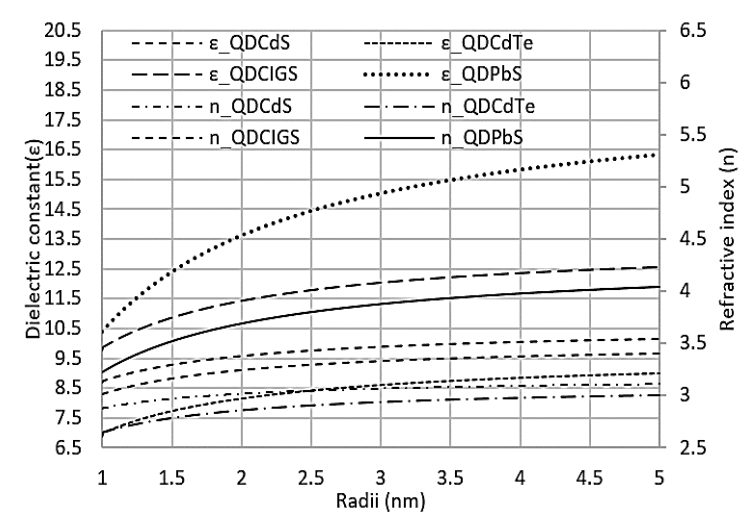

Figure 1. Radii effect on the refractive index and dielectric constant of quantum dot semiconductors $\mathrm{CdS}, \mathrm{CdTe}, \mathrm{CIGS}$ and $\mathrm{PbS}$

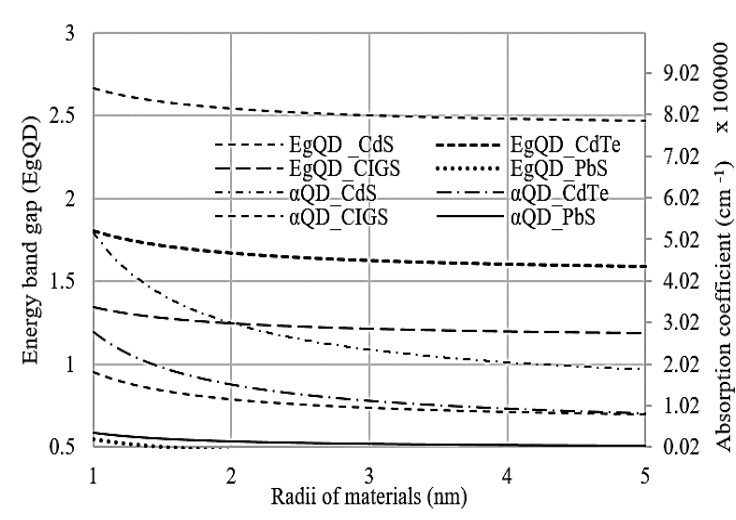

Figure 2. Radii effect on the absorption coefficient and energy band gap for quantum dot CdTe, CdS,

$\mathrm{PbS}$ and CIGS layers at thickness 700nm 


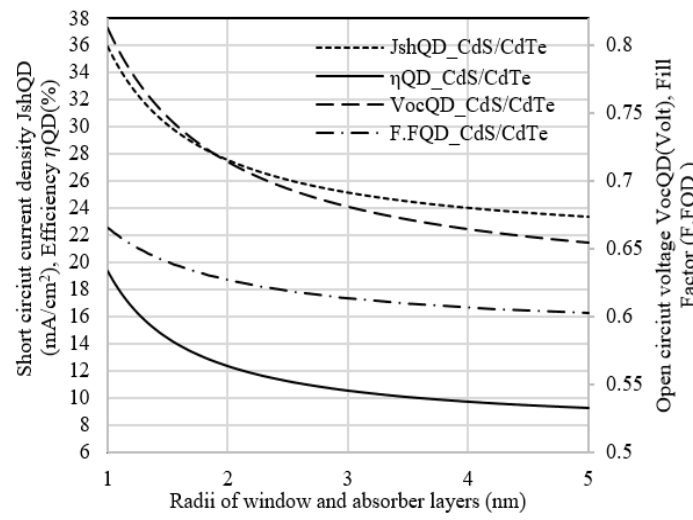

Figure 3. Quantum dots CdS and CdTe radii effect on the performance of heterojunction quantum dot $\mathrm{SnO}_{2} / \mathrm{QDCdS} / \mathrm{QDCdTe} / \mathrm{Cu}$ thin film solar cell

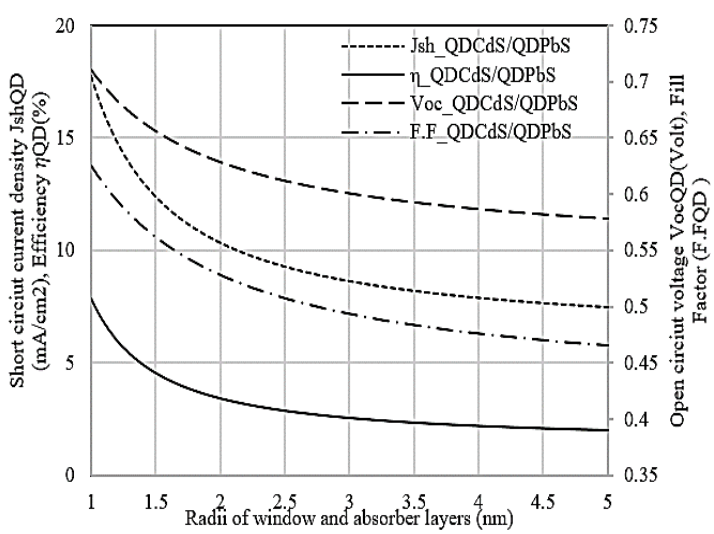

Figure 5. Quantum dots $\mathrm{CdS}$ and $\mathrm{PbS}$ radii effect on the performance of heterojunction quantum dot ITO/QDCdS/QDPbS/Au thin film solar cell

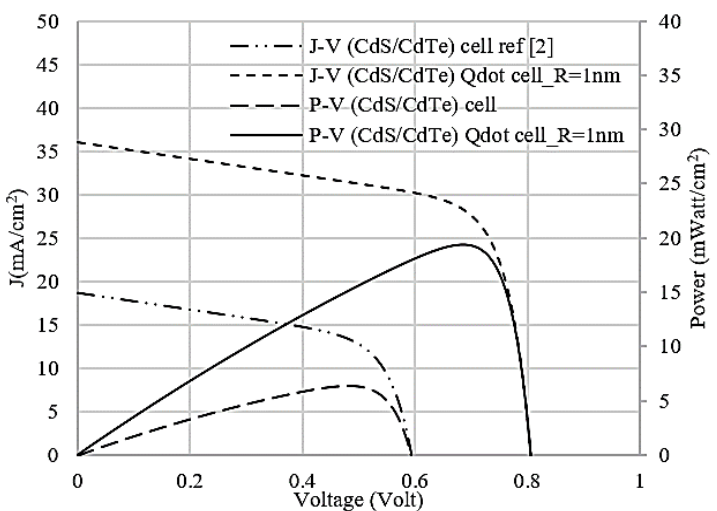

Figure 7. J-V and $\mathrm{P}-\mathrm{V}$ characteristics of practical sub micro $\mathrm{SnO}_{2} / \mathrm{CdS} / \mathrm{CdTe} / \mathrm{Cu}$ model and proposal heterojunction quantum dot $\mathrm{SnO}_{2} / \mathrm{QDCdS} / \mathrm{QDCdTe} / \mathrm{Cu}$ thin film solar cell

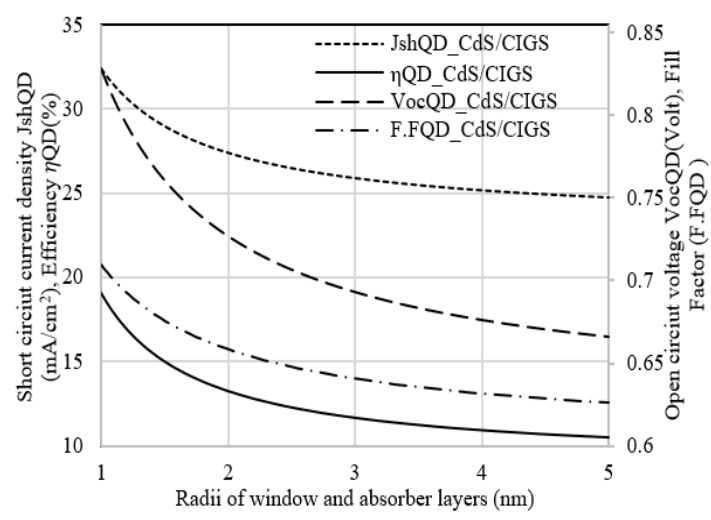

Figure 4. Quantum dots CdS and CIGS radii effect on the performance of heterojunction quantum dot

$\mathrm{ZnO/QDCdS/QDCIGS/Mo} \mathrm{thin} \mathrm{film} \mathrm{solar} \mathrm{cell}$

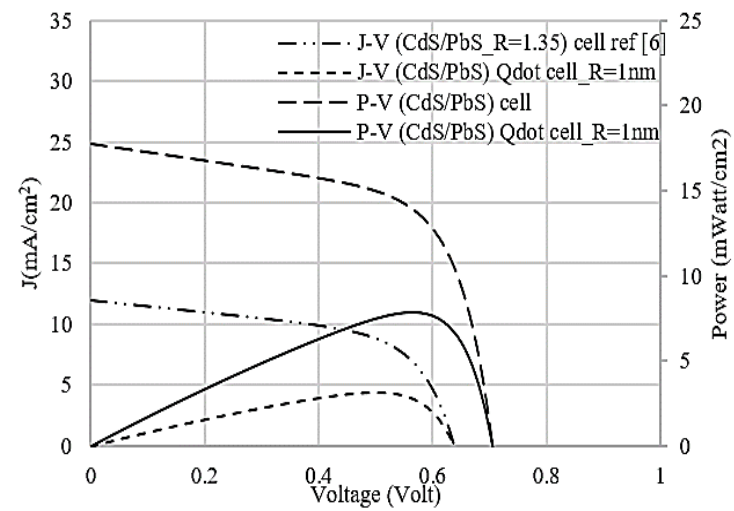

Figure 6. J-V and P-V characteristics of practical heterojunction quantum dot absorber layer $\mathrm{CdS} / \mathrm{QDPbS}$ model and proposal quantum dot QDCdS/QDPbS thin film solar cell

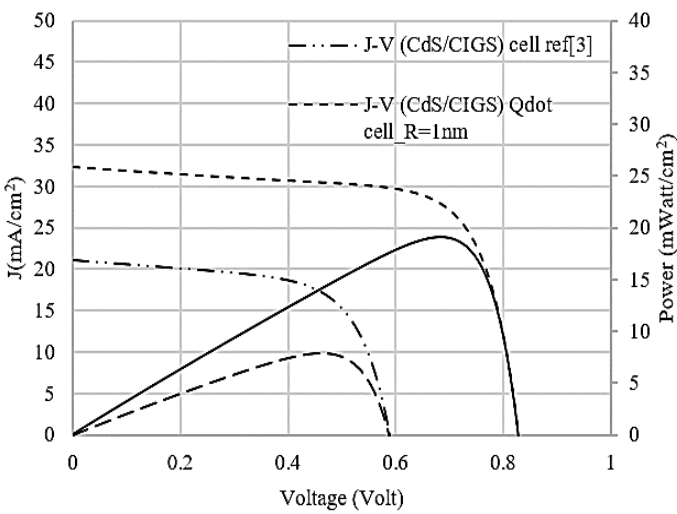

Figure $8 . \mathrm{J}-\mathrm{V}$ and $\mathrm{P}-\mathrm{V}$ characteristics of practical sub micro $\mathrm{ZnO} / \mathrm{CdS} / \mathrm{CIGS} / \mathrm{Mo}$ model and proposal heterojunction quantum dot

$\mathrm{ZnO/QDCdS/QDCIGS/Mo} \mathrm{thin} \mathrm{film} \mathrm{solar} \mathrm{cell}$ 
Table 4. Comparison between efficiency and electric properties of traditional models and heterojunction quantum dot proposal models at room temperature

\begin{tabular}{ccccc}
\hline & $\begin{array}{c}\text { Open Circuit } \\
\text { Voltage Vells }\end{array}$ & $\begin{array}{c}\text { Short Circuit Current } \\
\text { Density J J }\left(\mathrm{mA} / \mathrm{cm}^{2}\right)\end{array}$ & $\begin{array}{c}\text { Fill Factor } \\
\text { F.F }\end{array}$ & $\begin{array}{c}\text { Efficiency } \\
(\%)\end{array}$ \\
\hline CdS/ (QDPbS_R=1.35nm) [3] & 0.63 & 12 & 0.43 & 3.3 \\
(QDCdS/QDPbS)_R=1nm & 0.71 & 17.75 & 0.63 & 7.88 \\
(CdS/CdTe) [4] & 0.58 & 18.6 & 0.65 & 4.7 \\
(QDCdS/QDCdTe)_R=1nm & 0.81 & 35.91 & 0.67 & 19.36 \\
(CdS/CIGS) [5] & 0.59 & 21 & 0.685 & 8.1 \\
(QDCdS/QDCIGS)_R=1nm & 0.83 & 32.43 & 0.71 & 19.05 \\
\hline
\end{tabular}

\section{THERMAL EFFICIENCY ANALYSIS}

Table 5 depicts the thermal effect on efficiency of proposal heterojunction quantum dot $\mathrm{SnO} / \mathrm{QDCdS} / \mathrm{QDCdTe} / \mathrm{Cu}, \mathrm{ZnO} / \mathrm{QDCdS} / \mathrm{QDCIGS/Mo,} \mathrm{ITO/QDCdS/QDPbS/Au} \mathrm{thin} \mathrm{film} \mathrm{solar} \mathrm{cells} \mathrm{at}$ various radii of window and absorber layer materials $\mathrm{CdS}$, CdTe. The energy conversion efficiencies of heterojunction quantum dots proposal thin film solar cells have been higher than the efficiency of practical models $\mathrm{ZnO} / \mathrm{CdS} / \mathrm{CIGS} / \mathrm{Mo}$, ITO/CdS/QDPbS/Au, $\mathrm{SnO} 2 / \mathrm{CdS} / \mathrm{CdTe} / \mathrm{Cu}$ thin film solar cells under high thermal conditions.

Table 5. Comparison between proposal selected HJQD thin film solar cells and traditional practical previous models

\begin{tabular}{|c|c|c|c|c|c|}
\hline \multirow{2}{*}{ Solar Cells } & \multicolumn{5}{|c|}{ Efficiency $\%$} \\
\hline & $300 \mathrm{~K}$ & $330 \mathrm{~K}$ & $350 \mathrm{~K}$ & $370 \mathrm{~K}$ & $400 \mathrm{~K}$ \\
\hline ITO/CdS/QDPbS/Au & 1.47 & 1.25 & 1.11 & 0.98 & 0.82 \\
\hline $\mathrm{SnO}_{2} / \mathrm{CdS} / \mathrm{CdTe} / \mathrm{Cu}$ & 6.15 & 5.26 & 4.69 & 4.13 & 3.32 \\
\hline \multirow[t]{2}{*}{$\mathrm{ZnO} / \mathrm{CdS} / \mathrm{CIGS} / \mathrm{Mo}$} & 8.005 & 6.61 & 5.74 & 4.90 & 3.71 \\
\hline & \multicolumn{5}{|c|}{ Efficiency at radii $1 \mathrm{~nm}$} \\
\hline ITO/QDCdS/QDPbS/Au & 7.88 & 6.33 & 5.43 & 4.63 & 3.62 \\
\hline $\mathrm{SnO}_{2} / \mathrm{QDCdS} / \mathrm{QDCdTe} / \mathrm{Cu}$ & 19.36 & 17.34 & 16.03 & 14.75 & 12.88 \\
\hline \multirow[t]{2}{*}{ ZnO/QDCdS/QDCIGS/Mo } & 19.05 & 16.40 & 14.81 & 13.31 & 11.17 \\
\hline & \multicolumn{5}{|c|}{ Efficiency at radii $1.5 \mathrm{~nm}$} \\
\hline ITO/QDCdS/QDPbS/Au & 4.57 & 3.72 & 3.22 & 2.78 & 2.5 \\
\hline $\mathrm{SnO}_{2} / \mathrm{QDCdS} / \mathrm{QDCdTe} / \mathrm{Cu}$ & 14.38 & 12.82 & 11.79 & 10.78 & 9.29 \\
\hline \multirow[t]{2}{*}{ ZnO/QDCdS/QDCIGS/Mo } & 15.08 & 12.89 & 11.52 & 10.22 & 8.40 \\
\hline & \multicolumn{5}{|c|}{ Efficiency at radii $2 \mathrm{~nm}$} \\
\hline ITO/QDCdS/QDPbS/Au & 3.43 & 2.82 & 2.45 & 2.13 & 1.71 \\
\hline $\mathrm{SnO}_{2} / \mathrm{QDCdS} / \mathrm{QDCdTe} / \mathrm{Cu}$ & 12.32 & 10.94 & 10.03 & 9.14 & 7.83 \\
\hline \multirow[t]{2}{*}{ ZnO/QDCdS/QDCIGS/Mo } & 13.36 & 11.34 & 10.08 & 8.89 & 7.19 \\
\hline & \multicolumn{5}{|c|}{ Efficiency at radii $3 \mathrm{~nm}$} \\
\hline ITO/QDCdS/QDPbS/Au & 2.56 & 2.12 & 1.86 & 1.63 & 1.32 \\
\hline $\mathrm{SnO}_{2} / \mathrm{QDCdS} / \mathrm{QDCdTe} / \mathrm{Cu}$ & 10.50 & 9.29 & 8.49 & 7.71 & 6.6 \\
\hline ZnO/QDCdS/QDCIGS/Mo & 11.79 & 9.93 & 8.78 & 7.68 & 6.11 \\
\hline
\end{tabular}

\section{CONCLUSION}

The decrease in the grain size of CdTe, CIGS, CdS, PbS semiconductors to quantum dot size decreased the dielectric constant and refractive index. Whatever, using quantum dot size of CdTe, CIGS, $\mathrm{CdS}, \mathrm{PbS}$ semiconductors increased the absorption coefficient of layers and energy band gap. Window and absorber layers' materials in quantum size enhanced the energy conversion efficiency, fill factor, short circuit current density, open circuit voltage of $\mathrm{SnO}_{2} / \mathrm{CdS} / \mathrm{CdTe} / \mathrm{Cu}$, ITO/CdS/QDPbS/Au and ZnO/CdS/CIGS/Mo thin film solar cells traditional models that are having sub-micro absorber layers' thicknesses and low efficiencies. Moreover, the reduction in radii of window and absorber layers materials in quantum dot size to be $1 \mathrm{~nm}$ is the best radius for enhancing the performance of heterojunction quantum dot ITO/QDCdS/QDPbS/Au, ZnO/QDCdS/QDCIGS/Mo and $\mathrm{SnO}_{2} / \mathrm{QDCdS} / \mathrm{QDCdTe} / \mathrm{Cu}$ cells due to increasing the energy band gap of absorber layer and increasing absorption of window and absorber layers which lead to decreasing the recombination and increasing the open circuit voltage, short circuit current density, output power density. Decreasing the size of quantum dot window and absorber layers' materials enhanced the performance of HJQD proposal selected cells at high temperatures. 


\section{ACKNOWLEDGEMENTS}

The present work was supported by Nanotechnology Research Center at Aswan University that is established by aiding the Science and Technology Development Fund (STDF), Egypt, Grant No: Project ID 505, 2009-2011.

\section{REFERENCES}

[1] T. Lee, A. Ebong, "A review of Thin Film Solar Cell Technologies and Challenges," Renewable and Sustainable Energy Reviews, Elsevier, Volume 70, pp. 1286-1297, April 2017.

[2] Z. Bai, J. Yang, S. DePba and D.Wang, "Thin Film CdTe Solar Cells With an Absorber Layer Thickness in Microand Sub-Micrometer scale," Applied Physics Letters, Volume 99, Issue 14, 2011.

[3] O. lundberg, M. Bodegard and L.Stolt, "Influence of the $\mathrm{Cu}(\mathrm{In}, \mathrm{Ga}) \mathrm{Se} 2$ Thickness and Grading on Solar Cell Performance," Progress in Photopholatics: Research and Apblication, Vol. 11, No. 2, pp.77 - 88, 2003.

[4] A. Nozik, "Nanoscience and Nanostructures for Photovoltaics and Solar Fuels. Nano," Nano Letters, Vol. 10, No. 8, pp. 2735-2741, 2010.

[5] K. Ebrahim, "Quantum Dots Solar Cells," InTech Solar Cells New Approaches and Reviews, Vol. 31, pp.303-331 2015.

[6] K. Bhandari, P. Roland, H. Mahabaduge, N. Haugen, C. Grice, "Thin Film Solar Cells Based on the Heterojunction of Colloidal PbS Quantum Dots with CdS," Solar Energy Materials \& Solar Cells. Elsevier, Vol. 117, pp. 476-482, 2013.

[7] M. El-Nahass, G.M. Youssef and Z.Sohaila, "Structural and Optical Characterization of CdTe Quantum Dots Thin Films," Journal of Alloys and Compounds. Elsevier, Vol. 604, pp.253-259, 2014.

[8] P. Singh, N. Ravindra, "Temperature Dependence of Solar Cell Performance -an analysis," Solar Energy Materials \& Solar Cells. Elsevier, Vol. 101, pp. 36-45, 2012.

[9] Y. Liao, S. Yikuo, W. Tyng, F. Lai, D. Hsieh, "Observation of Unusual Optical Transitions in Thin-Film $\mathrm{Cu}(\mathrm{In}, \mathrm{Ga}) \mathrm{Se} 2$ Solar Cells,” Optics Express, Vol. 20, Issue S6, pp. A836-A842, 2012.

[10] N. Ravindra, S. Auluck, and V. Srivastava, "Temperature Dependence of the Energy Gap in PbS, PbSe, and PbTe," Physica Status Solidi, Vol. 52, Issue 2, 1979.

[11] J. Jimenez, W. Tomm, "Spectroscopic Analysis of Optoelectronic Semiconductors," Springer series in optical science, pp.27, 2016.

[12] B. K. Ridley, "Quantum Processes in Semiconductors," 4th Edition. Oxford Science Publications, Ch.16, Pp.418, 2013.

[13] M.A. Mannan, M.S. Anjan and M.Z. Kabir, "Modeling of Current-Voltage Characteristics of Thin Film Solar Cells," Solid-State Electronics. Elsevier, Vol. 63, Issue 1, pp. 49-54, 2011.

[14] R. Das, S. Pandey, "Comparison of Optical Properties of Bulk and Nano Crystalline Thin Films of CdS Using Different Precursors," International Journal of Material Science, Vol. 1, Issue 1, pp. 35-40, 2011.

[15] M. Sultan and N. Sultana, "Analysis of Reflectance and Transmittance Characteristics of Optical Thin Film for Various Film Materials, Thicknesses and Substrates," J Electr Electron Sys, Vol. 4, Issue 3, 2015.

[16] C. Noguez, "Optical Properties of Isolated and Supported Metal Nanoparticles," Optical Materials. Elsevier, Vol. 27, Issue 7, pp. 1204-12011, 2005.

[17] T. Sau, A. Rogach, "Complex Shaped Metal Nanoparticles: Bottom-Up Syntheses and Applications," Wiley-VCH Verlag GmbH \& Co. KGaA, pp.369, 2012.

[18] Y. Yang, X. Sun, B.J. Chen, T.Chen, C.Sun B.Tay, Z. Sun, "Refractive Indices of Textured Indium Tin Oxide and Zinc Oxide Thin Films," Thin Solid Films. Elsevier, Vol. 510, Issue 1-2, pp. 95-101, 2006.

[19] R. Shannona, O. Medenbachb, R. Fischerc, "Refractive Index and Dispersion of Fluorides and Oxides," Journal of Physical and Chemical Reference Data, Vol. 31, No. 4, Pp.931-969, 2002.

[20] H.A. Mohamed, "Theoretical Study of the Efficiency of CdS/PbS Thin Film Solar Cells," Solar Energy. Elsevier, Vol. 108, pp. 360-369, 2014.

[21] R. Prakash, S. Singh, "Designing and modelling of solar photovoltaic cell and array," IOSR Journal of Electrical and Electronics Engineering (IOSR-JEEE), Vol. 6,Pp 35-40, 2016.

[22] S. P. Mouri, S. N. Sakib, S. Hoque and M. S. Kaiser, "Theoretical efficiency and cell parameters of AlAs/GaAs/Ge based new multijunction solar cell," 2016 3rd International Conference on Electrical Engineering and Information Communication Technology (ICEEICT), Dhaka, pp. 1-6, 2016.

[23] F. Micheal, "Radiative Heat Transfer," 3rd edition. Elsevier, pp. 77, 2013.

[24] B. Yanchuk, "Laser Cleaning: Optical Physics," Applied Physics and Materials Science, pp.136, 2002.

[25] G. Handbush, "Mo Molybdenum: Physical Properties," Part 2. Electrochemistry 8th edition. Springer, pp.62, 2013.

[26] M. Asaduzzaman, M. Hasan and A. Newaz, "An Investigation into The Effects of Band Gap and Doping Concentration on $\mathrm{Cu}(\mathrm{In}, \mathrm{Ga}) \mathrm{Se} 2$ Solar Cell Efficiency," Springer Plus, Vol. 5, No. 1, pp. 1-8, 2016. 